\title{
Manajemen Rekayasa Lalu Lintas Pada Kawasan Pasar Bambu Kuning Di Kota Bandar Lampung
}

\author{
Eddi, Cardova, R Caesario Boing \\ Politeknik Pelayaran Surabaya \\ Email: Eddi65@gmail.com
}

\begin{abstract}
ABSTRAK
Perkembangan lalu lintas akan sangat dipengaruhi oleh tata ruang dan fungsi yang berada di bagian perkotaan. Agar tidak terjadi penurunan bagi tingkat pelayanan di masyarakat, maka perkembangan sistem jaringan perlu mengimbangi bagaimana perkembangan ekonomi serta penduduk yang ada di dalamnya. Penelitian ini dilakukan untuk menemukan solusi permasalahan lalu lintas di Kawasan Pasar Bambu Kuning melalui manajemen rekayasa lalu lintas. Penelitian dibantu menggunakan program computer CONTRAM 5.0. Hasil dari penelitian menunjukkan bahwa melalui pembuatan rekayasa dua skenario, scenario nomor dua memberikan hasil yang lebih baik dibandingkan scenario 1, di mana keduanya sama-sama memberikan hasil yang lebih baik dibandingkan kondisi yang ada pada saat ini.

Kata Kunci: Lalu Lintas, Manajemen Rekayasa, Jalan, Kawasan Pasar Bambu Kuning
\end{abstract}

\begin{abstract}
Traffic development will be greatly influenced by spatial planning and functions in urban areas. In order to avoid a decline in the level of service in the community, the development of the network system needs to keep pace with the economic development and the population in it. This research was conducted to find solutions to traffic problems in the Pasar Bambu Kuning area through traffic engineering management. The research was assisted using the CONTRAM 5.0 computer program. The results of the study show that through the engineering of two scenarios, scenario number two gives better results than scenario 1, both of which give better results than the current conditions.
\end{abstract}

Keywords: Traffic, Engineering Management, Road, Yellow Bamboo Market Area

\section{A. PENDAHULUAN}

Tata ruang dan fungsi pada bagian kota sangat mempengaruhi perkembangan lalu lintas pada bagian kota tersebut serta mempengaruhi pula keadaan lalu lintas di sekitarnya. Sehingga tata ruang dan fungsi pada bagian-bagian kota serta perkembangannya tidak lepas dari segi kuantitas maupun kualitasnya.

Perkembangan sistem jaringan jalan yang ada pada suatu kota harus dapat mengimbangi 
perkembangan ekonomi dan penduduk yang cepat sehingga tidak terjadi penurunan tingkat pelayanan yang diakibatkan belum memadainya ruas jalan yang ada. Karena salah satu fungsi ruas jalan yaitu sebagai penghubung antar wilayah yang merupakan prasarana yang cukup penting bagi masyarakat wilayah sekitarnya dalam menjalankan aktivitasnya. Menurut Undang-Undang Nomor 38 Tahun 2004, Jalan adalah prasarana transportasi darat yang meliputi segala bagian jalan, termasuk bangunan pelengkap dan perlengkapannya yang diperuntukkan bagi lalu lintas, yang berada pada permukaan tanah, di atas permukaan tanah, di bawah permukaan tanah dan/atau air, serta di atas permukaan air, kecuali jalan kereta api, jalan lori, dan jalan kabel.

Menurut Undang-Undang Nomor 22 Tahun 2009, Lalu Lintas didefinisikan sebagai gerak kendaraan dan orang di ruang lalu lintas. Ketidakseimbangan antara pertumbuhan jumlah kendaraan dengan pertumbuhan ruang jalan mengakibatkan peningkatan arus lalu lintas sehingga menyebabkan kepadatan lalu lintas atau kemacetan. Kemacetan lalu lintas terjadi bila pada kondisi lalu lintas di jalan raya mulai tidak stabil, kecepatan operasi relatif menurun cepat akibat adanya hambatan yang timbul dan kebebasan bergerak relatif kecil (Sumadi, 2006). Hal serupa juga dikemukakan oleh Tamin, 2008, yaitu apabila kepadatan lalu lintas meningkat, maka kecepatan suatu kendaraan semakin menurun.

Kota Bandar Lampung telah memiliki ruas jalan yang cukup baik. Namun disatu sisi pembangunan yang terjadi pada kota ini tidak merata, sebagai contoh daerah barat Kota Bandar Lampung yang berbatasan dengan Kabupaten Pesawaran masih kurang pembangunannya. Hal ini dikarenakan tata guna lahan yang masih rendah akan pemukiman karena kurangnya perhatian pemerintah kota. Oleh karena itu perencanaan pemerataan pembangunan sangat dibutuhkan di Kota Bandar Lampung.

Kondisi kemacetan yang terjadi di Kota Bandar Lampung tidak semakin membaik melainkan semakin memburuk. Hal ini dikarenakan jumlah kendaraan yang selalu bertambah dan tidak diimbangi dengan pengaturan lalu lintas serta perluasan area jalan raya sehingga kapasitas jalan yang disediakan tidak dapat menampung volume lalu lintas yang tinggi terutama pada jamjam sibuk saat masyarakat melakukan aktivitas seperti bekerja, sekolah dan kegiatan lainnya untuk memenuhi kebutuhannya sehari-hari. Kemacetan biasanya terjadi pada kawasan-kawasan tertentu yang dapat menjadi tarikan bagi masyarakat seperti kawasan perdagangan atau kawasan komersil.

Kawasan Pasar Bambu Kuning di Kota Bandar Lampung merupakan salah satu pilihan tempat bagi warga Kota Bandar Lampung dalam rangka memenuhi kebutuhan harian, mingguan, maupun bulanan yang bersifat primer maupun sekunder. Dengan berlokasikan di wilayah Central Business District (CBD). Pasar yang terletak di kecamatan Tanjung Karang Pusat ini memiliki posisi yang sangat strategis, karena apabila dilihat dari letaknya yang berada tepat di jantung perkotaan Kota Bandar Lampung. Pasar ini diramaikan oleh para pengunjung dan penjual dimulai pukul 08.00 WIB hingga pukul 17.00 WIB, sehingga pada ruas-ruas jalan di kawasan ini setiap harinya selalu dipadati oleh pengunjung. Tingginya pergerakan lalu lintas di sekitar pasar ini menyebabkan lalu lintas semakin padat sehingga tingkat pelayanan ruas jalan menjadi buruk. Selain, tingginya hambatan samping seperti adanya parkir di badan jalan, pedagang kaki lima, kendaraan bongkar muat di pinggir jalan menjadi permasalahan lalu lintas pada Pasar Bambu Kuning.

Kinerja ruas jalan di kawasan pasar Bambu Kuning dapat dikategorikan bermasalah karena sebagian besar memiliki kinerja yang cukup buruk, diantaranya adalah Ruas Jalan Bukit Tinggi, Ruas Jalan Imam Bonjol, ruas jalan RA Kartini yang disebabkan karena faktor hambatan samping yang tinggi.

Pada Ruas Jalan Bukit Tinggi merupakan jalan lokal sebagai akses masuk menuju 
pertokoan ataupun ruko yang tersebar di Kawasan pasar, pada jalan tersebut terdapat PKL yang berjualan di depan ruko ataupun pertokoan sehingga hal tersebut tentunya sangat meminimalkan akses menuju tempat tersebut, dan juga parkir kurang adanya penataan yang seharusnya terkodinir pada suatu titik yang telah di tetapkan sehingga hal tersebut memunculkan kesemerautan atau kekacauan yang timbul.

Pada Ruas jalan Imam bonjol merupakan jalan kolektor yang terdapat lokasi Pasar Bambu Kuning pada jalan kolektor ini juga memiliki hambatan samping seperti PKL dan juga para pengunjung yang parkir sembarangan di sepanjang badan jalan. Pada Ruas Jalan RA Kartini merupakan jalan arteri yang memiliki kinerja yang cukup buruk dikarenakan jalan tersebut jalan berstatus jalan provinsi sehingga banyak kendaraan ataupun lalu lintas yang melewati jalan tersebut. Karena terdapat permasalahan pada Kawasan tersebut maka diperlukan kajian untuk mendapatkan solusi yang tepat untuk memecahkan masalah yang ada pada Kawasan tersebut dari permasalahan di atas penulis akan melakukan penelitian lalu lintas mengenai manajemen rekayasa lalu lintas pada Kawasan Pasar Bambu Kuning di Kota Bandar Lampung.

\section{B. KAJIAN LITERATUR}

\section{Definisi Manajemen dan Rekayasa Lalu Lintas}

Penelitian ini dilakukan berdasarkan peraturan yang berlaku di Indonesia saat ini diantaranya Undang - Undang Nomor 22 tahun 2009, Peraturan Pemerintah Nomor 32 Tahun 2011 dan Peraturan Menteri Nomor 69 Tahun 2015, dalam peraturan tersebut dijelaskan bahwa pengertian Manajemen dan rekayasa lalu lintas adalah serangkaian usaha dan kegiatan yang meliputi perencanaan, pengadaan, pemasangan, pengaturan, dan pemeliharaan fasilitas perlengkapan jalan dalam rangka mewujudkan, mendukung dan memelihara keamanan, keselamatan, ketertiban, dan kelancaran lalu lintas. Manajemen dan rekayasa lalu lintas sebagaimana dimaksud meliputi kegiatan:
a) Perencanaan;
b) Pengaturan;
c) Perekayasaan;
d) Pemberdayaan;
e) Pengawasan.

Dalam Peraturan Pemerintah Nomor 32 Tahun 2011 Tentang Manajemen Dan Rekayasa, Analisis Dampak, serta Manajemen Kebutuhan Lalu Lintas, Manajemen dan Rekayasa Lalu Lintas dilaksanakan untuk mengoptimalkan penggunaan jaringan Jalan dan gerakan Lalu Lintas dalam rangka menjamin Keamanan, Keselamatan, Ketertiban, dan Kelancaran Lalu Lintas dan Angkutan Jalan. Manajemen dan Rekayasa Lalu Lintas sebagaimana dimaksud di atas dilakukan dengan:

a) Penetapan prioritas angkutan massal melalui penyediaan lajur atau jalur atau jalan khusus;

b) Pemberian prioritas keselamatan dan kenyamanan Pejalan Kaki;

c) Pemberian kemudahan bagi penyandang cacat;

d) Pemisahan atau pemilahan pergerakan arus Lalu Lintas berdasarkan peruntukan lahan, mobilitas, dan aksesibilitas;

e) Pemaduan berbagai moda angkutan;

f) Pengendalian Lalu Lintas pada persimpangan;

g) Pengendalian Lalu Lintas pada ruas Jalan; dan/atau

h) Perlindungan terhadap lingkungan.

Sasaran dilakukan kegiatan manajemen lalu lintas sendiri adalah: 
a) Mengatur dan menyederhanakan lalu lintas dengan melakukann pemisahan terhadap tipe, kecepatan dan pemakai jalan yang berbeda untuk meminimumkan gangguan terhadap lalu lintas.

b) Mengurangi tingkat kemacetan lalu lintas dengan menaikkan kapasitas atau mengurangi volume lalu lintas pada suatu jalan.

c) Melakukan optimasi ruas jalan dengan menentukan fungsi dari jalan dan control terhadap aktivitas-aktivitas yang tidak cocok dengan fungsi jalan tersebut.

\section{Kinerja Lalu Lintas}

Kinerja lalu lintas perkotaan dapat dinilai dengan menggunakan parameter lalu lintas sebagai berikut:

a) Untuk ruas jalan, dapat berupa V/C Ratio, kecepatan dan kepadatan lalu lintas.

b) Untuk persimpangan dapat berupa tundaan dan kapasitas simpang. (Tamin, 2008) Kinerja yang dibutuhkan dalam studi ini adalah sebagai berikut:

a) V/C Ratio merupakan perbandingan antara volume dan kapasitas yang menunjukkan kondisi unjuk kerja ruas jalan dalam melayani volume lalu lintas yang ada.

b) Kecepatan perjalanan rata-rata, dapat menunjukkan waktu tempuh dari titik asal ke titik tujuan di dalam wilayah pengaruh yang akan menjadi tolak ukur dalam pemilihan rute perjalanan serta analisis ekonomi.

c) Tingkat pelayanan yang menjadi indikator yang mencakup gabungan beberapa parameter baik secara kuantitatif maupun kualitatif dari ruas jalan dan persimpangan. Penentuan tingkat pelayanan ini akan disesuaikan dengan kondisi lalu lintas yang ada.

Pengukuran kinerja lalu lintas yang dilakukan di dalam penelitian ini diambil berdasarkan Pedoman Buku Manual Kapasitas Jalan Indonesia (MKJI) 1997. Di mana pengukuran kinerja lalu lintas yang dilakukan terbagi atas pengukuran kinerja ruas jalan dan kinerja pada persimpangan.

\section{Kinerja Ruas Jalan}

Indikator kinerja ruas jalan yang dimaksud adalah perbandingan volume per kapasitas (V/C Ratio), kecepatan dan kepadatan lalu lintas. Tiga karakteristik ini kemudian di pakai untuk mencari tingkat pelayanan (level of service). Penjelasan untuk masing-masing indikator dijelaskan sebagai berikut:

a) Kapasitas Jalan

Berdasarkan Pedoman Buku Manual Kapasitas Jalan Indonesia (MKJI) 1997, menyatakan bahwa kapasitas jalan didefinisikan sebagai arus lalu lintas (stabil) maksimum yang dapat dipertahankan pada kondisi tertentu (geometri, distribusi arah, komposisi lalu lintas, dan faktor lingkungan). Untuk jalan dua-lajur dua-arah, kapasitas ditentukan untuk arus dua arah (kombinasi dua arah), tetapi untuk jalan dengan banyak lajur, arus dipisahkan per arah dan kapasitas ditentukan per lajur. Kapasitas ruas jalan dibedakan untuk jalan perkotaan, jalan luar kota, dan jalan bebas hambatan. Selain itu, ada dua faktor yang mempengaruhi nilai kapasitas suatu ruas jalan yaitu faktor jalan dan faktor lalu lintas. Faktor jalan yang dimaksud berupa lebar lajur, kebebasan samping, jalur tambahan atau bahu jalan, keadaan permukaan, alinyemen dan kelandaian jalan. Faktor lalu lintas yang dimaksud adalah banyaknya pengaruh berbagai tipe kendaraan terhadap seluruh kendaraan arus lalu lintas pada suatu ruas jalan. Hal ini juga diperhitungkan terhadap pengaruh satuan mobil penumpang (smp). Sedangkan kapasitas dasar yaitu kapasitas segmen jalan pada kondisi geometri, pola arus lalu lintas, dan faktor lingkungan yang ditentukan sebelumnya (ideal). 
b) Kecepatan

Sesuai dengan Pedoman Buku Manual Kapasitas Jalan Indonesia (MKJI) 1997, kecepatan didefinisikan dalam beberapa hal antara lain: Kecepatan tempuh adalah kecepatan rata-rata kendaraan (km/jam) arus lalu lintas dihitung dari panjang jalan dibagi waktu tempuh ratarata kendaraan yang melalui segmen jalan. Kecepatan tempuh digunakan sebagai ukuran utama kinerja segmen jalan, karena mudah dimengerti dan diukur, dan merupakan masukan yang penting untuk biaya pemakai jalan dalam analisa ekonomi

c) Kepadatan Ruas

Kepadatan dapat didefinisikan sebagai jumlah kendaraan rata-rata dalam ruang. Satuan kepadatan adalah kendaraan per $\mathrm{km}$ atau kendaraan-km per jam. Seperti halnya volume lalu lintas, kepadatan juga dapat dikaitkan dengan penyediaan jumlah lajur jalan (Tamin, 2008).

d) Tingkat Pelayanan

Tingkat pelayanan (Level Of Service, LOS) adalah ukuran yang menunjukkan karakteristik mobilitas suatu persimpangan, sebagaimana yang ditentukan oleh penundaan kendaraan, dan faktor sekunder, yaitu perbandingan volume/kapasitas. Khisty \& Lall, (2003).

\section{Kinerja Persimpangan}

Analisis yang akan dilakukan di persimpangan meliputi jenis pengendalian yang di terapkan dan pengukuran kinerja persimpangan tanpa lampu lalu lintas.

a) Komponen kinerja Persimpangan Tanpa Lampu Lalu Lintas Sesuai Pedoman Buku Manual Kapasitas Jalan Indonesia (MKJI) 1997 komponen kinerja persimpangan tidak berlampu lalu lintas terdiri dari kapasitas simpang, derajat kejenuhan, tundaan, dan peluang antrian.

b) Tundaan Lalu Lintas Jalan Utama (DTMA) adalah tundaan lalu lintas rata- rata semua kendaraan bermotor yang masuk persimpangan dari jalan utama. Tundaan lalu lintas jalan utama (DTMA) untuk simpang tidak bersinyal

c) Tundaan Lalu Lintas Jalan Minor adalah tundaan simpang rata-rata dan tundaan jalan utama rata-rata. Tundaan lalu lintas jalan minor (DTMI) untuk simpang tidak bersinyal

d) Tundaan Geometrik Simpang (DG) adalah tundaan geometrik rata-rata seluruh kendaraan bermotor yang masuk simpang. Tundaan lalu lintas jalan minor (DTMI) untuk simpang tidak bersinyal

e) Tundaan Simpang (D) adalah untuk simpang tidak bersinyal

f) Peluang Antrian (QP \%)

Rentang nilai peluang antrian QP \% ditentukan dari hubungan QP \% dan derajat kejenuhan DS serta ditentukan dengan grafik. Tingkat pelayanan pada persimpangan mempertimbangkan faktor tundaan dan kapasitas persimpangan

\section{Kinerja Jaringan Jalan}

Dalam penulisan penelitian ini, perangkat lunak CONTRAM 5,0 (Continous Traffic Assigment Model 5,0) digunakan untuk membuat model pembebanan lalu lintas. CONTRAM pada dasarnya menggunakan prinsip lintasan minimum (Shortest path) dan pengemudi diasumsikan telah mengenal kondisi lalu lintas yang ada, sehingga mereka akan memilih rute dengan waktu perjalanan minimum, kecuali untuk mobil penumpang umum yang mempunyai rute tetap. Berdasarkan pertimbangan waktu minimum, perjalanan kendaraan dari tempat asal ke tempat tujuan dibebankan ke masing - masing ruas yang membangun lintasan minimum tersebut 
menurut variasi waktu (interval). Selain variasi waktu, CONTRAM mengelompokkan kendaraan yang bergerak dari setiap pasangan asal tujuan dalam paket-paket kendaraan guna mengurangi lamanya waktu perhitungan.

\section{METODE}

Penelitian diawali dengan melakukan identifikasi masalah di wilayah studi. Kemudian data yang dibutuhkan dikumpulkan dengan pengumpulan data primer dari hasil survei dan data sekunder dari hasil PKL instansi terkait. Data kemudian di analisis dan dioleh menggunakan bantuan program komputer berupa CONTRAM 5.0 sebagai model pembebanan lalu lintas.

\section{HASIL DAN PEMBAHASAN}

\section{Analisis Permasalahan Kinerja Eksisting (Do Nothing)}

a) Kinerja Jaringan Eksisting

Pada kondisi eksisting ini dapat diidentifikasi permasalahan - permasalahan unjuk kerja jaringan jalan diwilayah studi. Setelah dilakukan analisa kinerja jaringan eksisting berdasarkan hasil dari survei di lapangan, maka dilakukan analisa kondisi eksisting dengan menggunakan perangkat lunak komputer. Agar hasil analisa dengan aplikasi tersebut dapat digunakan untuk analisa selanjutnya, terlebih dahulu dilakukan validasi. Pembebanan dilaksanakan dengan menggunakan bantuan Contram versi 5.0 dapat diketahui unjuk kerja jaringan jalan yang terdapat dilokasi penelitian yaitu pada kawasan Pasar Bambu Kuning Kota Bandar Lampung pada kondisi eksisting yang dapat dilihat pada Tabel V.1 sebagai berikut:

Tabel V. 1 Unjuk Kinerja Jaringan Jalan Eksisting

\begin{tabular}{|c|l|c|}
\hline No & \multicolumn{1}{|c|}{ Parameter } & Kinerja \\
\hline 1 & Total Waktu Perjalanan (detik) & 194.6 \\
\hline 2 & Jarak Perjalanan (smp-km) & 5762.4 \\
\hline 3 & $\begin{array}{l}\text { Kecepatan Perjalanan } \\
\text { (km/jam) }\end{array}$ & 29.3 \\
\hline 4 & Total Antrian (smp) & 0 \\
\hline
\end{tabular}

Dari tabel diatas kinerja jaringan jalan dapat diuraikan sebagai berikut :

1) Waktu Perjalanan

Waktu perjalanan adalah waktu yang dipergunakan oleh seluruh kendaraan untuk mencapai tujuan perjalanan. Dari tabel diatas dapat diketahui bahwa waktu perjalanan sebesar 194.6 detik.

2) Jarak Perjalanan

Jarak perjalanan adalah panjang jalan yang dilalui oleh seluruh kendaraan. Total Jarak perjalanan pada kawasan sebesar $5762.4 \mathrm{smp}-\mathrm{km}$.

3) Kecepatan Pejalanan

Kecepatan rata-rata pada kawasan setiap kendaraan sebesar 29km/jam.

4) Total Antrian

Total kendaraan yang mengalami antrian sebesar $0 \mathrm{smp}$.

b) Kinerja Ruas Jalan 
Tabel V. 2 Kinerja Ruas Jalan Eksisting

\begin{tabular}{|c|c|c|c|c|}
\hline \multirow{2}{*}{ No } & Nama Jalan & $\begin{array}{c}\text { v/c } \\
\text { Ratio }\end{array}$ & Kecepatan & \multirow{2}{*}{ LOS } \\
\cline { 4 - 5 } & & (Km/Jam) & \\
\hline 1 & Imam Bonjol & 0.97 & 31.1 & E \\
2 & RA Kartini & 0.71 & 45 & $\mathrm{C}$ \\
\hline
\end{tabular}

Dari tabel diatas, dapat diketahui tingkat pelayanan (Level of Service) ruas jalan Imam Bonjol adalah nilai E.

Selanjutnya di dalam upaya pemecahan masalah yang terjadi, maka langkah pertama adalah mengetahui penyebab penurunan unjuk kerja ruas - ruas jalan di atas, permasalahan yang terjadi di kawasan Pasar Bambu Kuning Kota Bandar Lampung tersebut disebabkan oleh Pedagang Kaki Lima dan parkir kendaraan motor yang berada di sepanjang ruas jalan Imam Bonjol.

\section{Tahap Pengusulan Skenario (Do Something)}

Dari hasil analisis dan beberapa permasalahan yang ada pada kawasan Pasar Bambu Kuning Kota Bandar Lampung, maka perlunya adanya alternatif pemecahan masalah yang merupakan Tahapan Pengaturan dalam Manajemen dan Rekayasa Lalu Lintas, hal tersebut digunakan dalam meningkatkan unjuk kinerja ruas serta kinerja jaringan jalan. Alternatif permecahan masalah tersebut dilakukan dengan berbagai skenario yang terdiri dari:

a) Skenario 1

Penanganan yang akan di lakukan pada Kawasan pasar bambu kuning yaitu berfokus pada jalan Imam Bonjol, skenario 1 dilakukan penertiban Pedagang Kaki Lima dan Pemindahan Parkir on street ke ruas jalan yang berada di belakang Pasar Bambu Kuning. Pada skenario ini terdapat dua point yang dapat mengubah nilai kapasitas yang kecil menjadi besar dari sebelumnya, hal ini di karenakan tidak adanya hambatan samping seperti Pedagang Kaki Lima dan Parkir on street sehingga trotoar yang semula menjadi lapak untuk berjualan para Pedagang Kaki Lima menjadi sebagaimana fungsinya dengan peruntukan bagi penguna pejalan kaki, dan juga parkir on street yang menggunakan bahu jalan dan Sebagian badan jalan menjadi hilang karna adanya pemindahan dan penertiban dilarang parkir. Dalam hal ini faktor hambatan samping (FCsf) berubah dari Very High menjadi Low.

Tabel V. 3 Perbandingan Nilai Kapasitas Eksisting dengan Skenario 1

\begin{tabular}{|c|c|c|c|}
\hline No & Nama Jalan & $\begin{array}{c}\text { Kapasitas } \\
\text { Eksisting }\end{array}$ & $\begin{array}{c}\text { Kapasitas Skenario } \\
1\end{array}$ \\
\hline 1 & Imam Bonjol & 2955 & 3516 \\
\hline
\end{tabular}

Dari analisis penggunaan aplikasi contram di dapat hasil pada skenario 1 diperoleh unjuk kerja adalah sebagai berikut: 


\section{Tabel V. 4 Unjuk Kinerja Jaringan Skenario 1}

\begin{tabular}{|c|l|c|}
\hline No & \multicolumn{1}{|c|}{ Parameter } & Kinerja \\
\hline 1 & Total Waktu Perjalanan (detik) & 126.6 \\
\hline 2 & Jarak Perjalanan (smp-km) & 5732.4 \\
\hline 3 & Kecepatan Perjalanan (km/jam) & 43 \\
\hline 4 & Total Antrian (smp) & 0 \\
\hline
\end{tabular}

1) Waktu Perjalanan

Waktu perjalanan adalah waktu yang dipergunakan oleh seluruh kendaraan untuk mencapai tujuan perjalanan. Dari tabel diatas dapat diketahui bahwa waktu perjalanan sebesar 126.6 detik.

2) Jarak Perjalanan

Jarak perjalanan adalah panjang jalan yang dilalui oleh seluruh kendaraan. Total Jarak perjalanan pada kawasan sebesar 5732.4 smp-km.

3) Kecepatan Pejalanan

Kecepatan rata-rata pada kawasan setiap kendaraan sebesar 43 km/jam

4) Total Antrian

Total kendaraan yang mengalami antrian sebesar $0 \mathrm{smp}$.

Dari hasil analisis penerapan skenario 1 dapat diperoleh kinerja ruas pada Kawasan Pasar Bambu Kuning dapat dillihat pada tabel berikut berikut:

Tabel V. 5 Kinerja Ruas Jalan Skenario 1

\begin{tabular}{|c|c|c|c|c|c|c|}
\hline \multirow{2}{*}{ Nama Ruas } & \multicolumn{3}{|c|}{ Eksisting } & \multicolumn{3}{c|}{ Skenario 1 } \\
\cline { 2 - 7 } & V/C & $\begin{array}{c}\text { Kecepatan } \\
(\mathrm{km} / \mathrm{jam})\end{array}$ & Los & V/C & $\begin{array}{c}\text { Kecepatan } \\
(\mathrm{km} / \mathrm{jam})\end{array}$ & Los \\
\hline $\begin{array}{c}\text { Imam } \\
\text { Bonjol }\end{array}$ & 0.97 & 31.1 & $\mathrm{E}$ & 0.82 & 51.4 & $\mathrm{D}$ \\
\hline
\end{tabular}

Dari table berikut dapat diketahui perbandingan nilai v/c ratio Eksisting dengan hasil Skenario 1, yang semula 0,97 menjadi 0,82 .

Tabel V. 6 Kinerja Simpang

\begin{tabular}{|c|l|c|c|c|}
\hline No & \multicolumn{1}{|c|}{ Nama Simpang } & $\begin{array}{c}\text { Derajat } \\
\text { Kejenuhan } \\
\text { (DS) }\end{array}$ & $\begin{array}{c}\text { Panjang Antrian } \\
\text { (M) }\end{array}$ & $\begin{array}{c}\text { Tundaan } \\
\text { (det/smp) }\end{array}$ \\
\hline 1 & $\begin{array}{l}\text { Simpang Pasar Bambu } \\
\text { Kuning }\end{array}$ & 0.48 & $11-24$ & 9.93 \\
\hline
\end{tabular}


Dari table berikut dapat diketahui bahwa kinerja simpang menjadi 0,48

b) Skenario 2

Pada Pasar Bambu Kuning terdapat satu titik sirkulasi untuk keluar masuk kendaraan baik mobil maupun motor yang akan parkir pada Kawasan pasar, yang dimana titik tersebut terletak di depan pasar Bambu Kuning yaitu di jalan Imam Bonjol. Dalam hal ini terdapat pengaruh pada kinerja ruas jalan Imam Bonjol yang menjadi problem ditambah dengan adanya hambatan samping seperti Pedagang Kaki Lima dan Parkir onstreet. Pada kondisi eksisting pasar Bambu Kuning ini akan dilakukan skenario perubahan kendaraan masuk dan kendaraan keluar, yang dimana sirkulasi keluar akan dialihkan pada belakang pasar yaitu ruas jalan Bukit Tinggi dan untuk sirkulasi masuk tetap berada pada depan pasar yaitu di ruas jalan Imam Bonjol. Pada skenario 2 ini dilakukan pelarangan Pedagang Kaki Lima, Pelarangan onstreet dan juga perubahan sirkulasi parkir keluar masuk pasar.

Dari analisis penggunaan aplikasi contram di dapat hasil pada skenario 2 diperoleh unjuk kerja adalah sebagai berikut:

\section{Tabel V. 7 Unjuk Kinerja Jaringan Skenario 2}

\begin{tabular}{|c|l|c|}
\hline No & \multicolumn{1}{|c|}{ Parameter } & Kinerja \\
\hline 1 & Total Waktu Perjalanan (detik) & 123.9 \\
\hline 2 & Jarak Perjalanan (smp-km) & 5702.4 \\
\hline 3 & $\begin{array}{l}\text { Kecepatan Perjalanan } \\
\text { (km/jam) }\end{array}$ & 46 \\
\hline 4 & Total Antrian (smp) & 0 \\
\hline
\end{tabular}

1) Waktu Perjalanan

Waktu perjalanan adalah waktu yang dipergunakan oleh seluruh kendaraan untuk mencapai tujuan perjalanan. Dari tabel diatas dapat diketahui bahwa waktu perjalanan sebesar 123.9 detik.

2) Jarak Perjalanan

Jarak perjalanan adalah panjang jalan yang dilalui oleh seluruh kendaraan. Total Jarak perjalanan pada kawasan sebesar 5702.4 smp-km.

3) Kecepatan Pejalanan

Kecepatan rata-rata pada kawasan setiap kendaraan sebesar 46 km/jam.

4) Total Antrian

Total kendaraan yang mengalami antrian sebesar $0 \mathrm{smp}$.

Dari hasil analisis penerapan skenario 2 dapat diperoleh kinerja ruas pada Kawasan Pasar Bambu Kuning dapat dillihat pada tabel berikut berikut:

Tabel V. 8 Kinerja Ruas Jalan Skenario 1

\begin{tabular}{|c|c|c|c|c|c|c|}
\hline \multirow{2}{*}{ Nama Ruas } & \multicolumn{3}{|c|}{ Eksisting } & \multicolumn{2}{c|}{ Skenario 2 } \\
\cline { 2 - 6 } & $\mathrm{V} / \mathrm{C}$ & $\begin{array}{c}\text { Kecepatan } \\
(\mathrm{km} / \mathrm{jam})\end{array}$ & Los & $\mathrm{V} / \mathrm{C}$ & $\begin{array}{c}\text { Kecepatan } \\
(\mathrm{km} / \mathrm{jam})\end{array}$ & Los \\
\hline
\end{tabular}




\begin{tabular}{|l|l|l|l|l|l|l|}
\hline Imam Bonjol & 0.97 & 31.1 & $\mathrm{E}$ & 0.82 & 51.4 & $\mathrm{D}$ \\
\hline
\end{tabular}

Dari table berikut dapat diketahui perbandingan nilai v/c ratio Eksistin dengan hasil Skenario 2, yang semula 0,97 menjadi 0,82 .

Tabel V. 9 Kinerja Simpang

\begin{tabular}{|c|c|c|c|c|}
\hline No & Nama Simpang & $\begin{array}{c}\text { Derajat } \\
\text { Kejenuhan } \\
\text { (DS) }\end{array}$ & $\begin{array}{c}\text { Panjang } \\
\text { Antrian (M) }\end{array}$ & $\begin{array}{c}\text { Tundaan } \\
\text { (det/smp) }\end{array}$ \\
\hline 1 & $\begin{array}{c}\text { Simpang Pasar } \\
\text { Bambu } \\
\text { Kuning }\end{array}$ & 0.47 & $10-23$ & 9.87 \\
\hline
\end{tabular}

Dari table berikut dapat diketahui bahwa kinerja simpang menjadi 0,47

\section{Perbandingan Kinerja Lalu Lintas}

Dari perbandingan ketiga skenario strategi penataan manajemen lalu lintas diatas dengan bantuan simulasi program Contram versi 5.0, maka dapat dibandingkan tiap kinerja jaringan pada Kawasan Pasar Bambu Kuning. Perbandingan unjuk kerja dari 3 skenario yang telah dilakukan terhadap kondisi eksisting adalah sebagai berikut:

\section{Tabel V. 10 Kinerja Jaringan Jalan Pada Skenario dan Eksisting}

\begin{tabular}{|c|c|c|c|c|}
\hline No & Parameter & Eksisting & $\begin{array}{c}\text { Skenario } \\
1\end{array}$ & $\begin{array}{c}\text { Skenario } \\
2\end{array}$ \\
\hline 1 & $\begin{array}{c}\text { Total Waktu Perjalanan } \\
\text { (detik) }\end{array}$ & 194.6 & 126.6 & 123.9 \\
\hline 2 & $\begin{array}{c}\text { Jarak } \\
\text { Perjalanan (smp-km) }\end{array}$ & 5762.4 & 5732.4 & 5702.4 \\
\hline 3 & $\begin{array}{c}\text { Kecepatan Perjalanan } \\
\text { (km/jam) }\end{array}$ & 29.3 & 43 & 46 \\
\hline 4 & \begin{tabular}{c} 
Total Antrian (smp) \\
\hline
\end{tabular} & 0 & 0 & 0 \\
\hline
\end{tabular}

Dari Tabel V.43 dapat diketahui bahwa untuk kondisi saat ini memang perlu untuk dibuat manajemen rekayasa lalu lintas karena memiliki total waktu perjalanan 194.6 detik, dengan 
kecepatan jaringan 29 km/jam. Setelah dilakukan skenario 1 yaitu penertiban Pedagang Kaki Lima dan pemindahan atau pelarangan parkir on street maka kecepatan jaringan meningkat $43 \mathrm{~km} / \mathrm{jam}$ dengan total waktu perjalanan 126.6 detik. Pada skenario 2 yaitu dengan penerapan dari skenario pertama ditambah dengan perubahan sirkulasi arus keluar masuk kendaraan parkir pada pasar Bambu Kuning dengan adanya perubahan kecepatan jaringan menjadi $46 \mathrm{~km} / \mathrm{jam}$ dengan total waktu perjalanan 123.9 detik, Skenario 2 merupakan penanganan terbaik yang dipilih berdasarkan penilaian parameter kinerja jaringan dan kebutuhan dari kondisi eksisting kawasan Pasar Bambu Kuning Kota Bandar Lampung.

\section{E. KESIMPULAN}

Berdasarkan hasil analisis yang telah dilakukan dengan permasalahan yang ada dapat disimpulkan bahwa kinerja lalu lintas di Kawasan Pasar Bambu Kuning yang diperoleh dari hasil pembebanan lalu lintas dengan menggunakan Skenario terbaik yaitu Skenario 2 dengan hasil berupa total waktu perjalanan 123,9 detik, jarak perjalanan 5702,4 smp-km, kecepatan jaringan 46 km/jam. Penanganan yang dilakukan terhadap kondisi Eksisting dilakukan 2 Skenario yaitu, Skenario 1 penghilangan Pedagang Kaki Lima dan Parkir onstreet pada ruas jalan Imam Bonjol. Skenario 2 yaitu penertiban Pedagang Kaki Lima, Larangan parkir onstreet dan pengaturan sirkulasi keluar masuk kendaraan parkir pada Pasar Bambu Kuning Melakukan peralihan sirkulasi keluar masuk pasar, yang dimana kondisi eksisting parkir keluar masuk pasar terdapat di depan pasar atau jalan Imam Bonjol, dalam penangganan ini dilakukan peralihan sirkulasi masuk menjadi di depan pasar atau jalan Imam Bonjol dan sirkulasi keluar pada belakang pasar yaitu di jalan Bukit Tinggi.

\section{REFERENSI}

1. Aji, K. 2017. Manajemen dan Rekayasa Lalu Lintas Pada Kawasan Pasar Lamongan Baru Skripsi DIV Transportasi Darat Sekolah Tinggi Transportasi Darat. Bekasi: STTD

2. Munawar, A. 2004, Manajemen Lalu Lintas Perkotaan, Beta Offset, Yogyakarta.

3. Nurviani, M. 2006. Manajemen dan Rekayasa Lalu Lintas Pasar Kota Solok. Skripsi DIV Transportasi Darat Sekolah Tinggi Transportasi Darat. Bekasi : STTD.

4. Republik Indonesia. 2009. Undang-Undang Nomor 22 Tahun 2009 tentang Lalu Lintas dan Angkutan Jalan. Jakarta: Departemen Perhubungan.

5. Republik Indonesia. 2011. Peraturan Menteri Perhubungan Nomor 96 Tahun 2015 tentang Pedoman Pelaksanaan Manajemen dan Rekayasa Lalu Lintas. Jakarta: Departemen Perhubungan.

6. Republik Indonesia. 2011. Peraturan Pemerintah Nomor 32 tentang Manajemen dan Rekayasa Lalu Lintas. Jakarta: Departemen Perhubungan.

7. Sampurna, H. 2012. Manajemen dan Rekayasa Lalu Lintas Pada Kawasan CBD di Kota Tanjung Pinang. Skripsi DIV Transportasi Darat Sekolah Tinggi Transportasi Darat, Bekasi : STTD.

8. Tamin, Ofyar Z. 2008, Perencanaan Permodelan dan Rekayasa Transportasi, ITB, Bandung. 